\title{
Helminth parasites in pigs: New challenges in pig production and current research highlights
}

\author{
A. Roepstorff*, H. Mejer, P. Nejsum, S.M. Thamsborg \\ Danish Centre for Experimental Parasitology, Department for Veterinary Disease Biology, Faculty of Life Sciences, University of Copenhagen, \\ Dyrlægevej 100, DK-1870 Frederiksberg C, Copenhagen, Denmark
}

\section{A R T I C L E I N F O}

\section{Keywords:}

Ascaris

Trichuris

Oesophagostomum

Pigs

Review

\begin{abstract}
A B S T R A C T
Helminths in pigs have generally received little attention from veterinary parasitologists, despite Ascaris suum, Trichuris suis, and Oesophagostomum sp. being common worldwide. The present paper presents challenges and current research highlights connected with these parasites.

In Danish swine herds, new indoor production systems may favour helminth transmission and growing knowledge on pasture survival and infectivity of A. suum and T. suis eggs indicates that they may constitute a serious threat to outdoor pig production. Furthermore, it is now evident that $A$. suum is zoonotic and the same may be true for $T$. suis. With these 'new' challenges and the economic impact of the infections, further research is warranted. Better understanding of host-parasite relationships and A. suum and T. suis egg ecology may also improve the understanding and control of human A. lumbricoides and $T$. trichiura infections.

The population dynamics of the three parasites are well documented and may be used to study phenomena, such as predisposition and worm aggregation. Furthermore, better methods to recover larvae have provided tools for quantifying parasite transmission. Thus, an on-going study using helminth naïve tracer pigs has surprisingly demonstrated that soil infectivity with $A$. suum and $T$. suis increases during the first 2-3 years after pasture contamination.

Though all three helminth species stimulate the Th2 arm of the immune system, Oesophagostomum seems weakly immunogenic, perhaps via specific modulation of the host immune system. A. suum and T. suis potently modulate the host immune response, up-regulating Th2 and down-regulating Th1. As a consequence, A. suum may compromise the efficacy of certain bacterial vaccines, whereas $T$. suis, which establish only short-term in humans, is a favourite candidate for down-regulating autoimmune Th1-related diseases in man.

Some basic research findings have offered new possibilities for future sustainable control measures. For example, the heredity of host resistance to A. suum and T. suis is so high that breeding for resistant pigs may be a possibility. Experimental studies have demonstrated that fermentable dietary carbohydrates have an antagonistic effect on Oesophagostomum and to a lesser extent on $T$. suis and A. suum, whereas egg-destroying microfungi may be used to inactivate the hard-shelled A. suum and T. suis eggs in the environment.

Helminth control in Denmark has previously relied solely on anthelmintic treatment in herds with low helminth transmission. When indoor transmission rates
\end{abstract}

\footnotetext{
* Corresponding author. Tel.: +45 35332746 .

E-mail address: aro@life.ku.dk (A. Roepstorff).
} 
increase, or in outdoor herds with high pasture contamination levels, medication may advantageously be combined with sustainable control measures, such as selected pig genomes, bioactive forages, and egg-destroying microfungi.

(C) 2011 Elsevier B.V. All rights reserved.

\section{Introduction}

Helminth parasites occur frequently in domestic pigs in all kinds of production systems and all around the World. Nevertheless, they have generally received much less attention from veterinary parasitologists than ruminant helminths. The main reason is presumably that most common porcine helminths very seldom cause clinical disease and therefore remain largely unrecognized by farmers and their veterinarians, whereas the most important ruminant parasites, if not controlled, will eventually lead to overt poor performance, severe economic losses or even fatal clinical disease. The major helminth species in temperate pig production include Ascaris suum (the large round worm), Trichuris suis (whipworm), and Oesophagostomum spp. (nodular worm).

Despite the common subclinical course of infections, pigs infected with one or more of the above mentioned species have reduced food utilisation and growth rate (Hale and Stewart, 1979; Hale et al., 1981, 1985) as well as a changed body composition (heavier plucks and less meat; Thamsborg, Mejer, Roepstorff, unpublished), while migration of $A$. suum larvae results in substantial liver condemnations (reviewed by Roepstorff, 2003), so for the financial perspective alone, pig helminths have to be controlled. However, there are other good reasons to study these parasites. A. suum and maybe T. suis are zoonoses and closely related to $A$. lumbricoides and $T$. trichiura, which infect 1221 and 795 million people worldwide, respectively (de Silva et al., 2003) and controlled infections in pigs make up the very best experimental animal models (Boes and Helwigh, 2000).

The present paper does not intend to provide a complete update on research on these three species. Instead, we present (1) some 'new' challenges (changed indoor pig productions systems; challenges in outdoor pig production systems; zoonotic aspects) and (2) some research highlights of importance for the basic understanding of host-parasite relationships (population dynamics; immunomodulation) as well as highlights on research areas, which may potentially be exploited in future sustainable control (genetics of host and worms; influence of diets with fermentable carbohydrates; inactivation of $A$. suum and T. suis eggs). Finally, we have some concluding remarks on (3) future helminth control.

\section{New challenges}

\subsection{Helminth challenges in relation to new trends in indoor pig housing}

A series of prevalence studies has demonstrated a common trend from high helminth prevalences and infection intensities in traditionally managed swine herds towards low prevalences and intensities in industrialised production systems (reviewed by Nansen and Roepstorff, 1999; Thamsborg and Roepstorff, 2003). Thus, it is common to find 5-10 species and high infection levels in (semi-)free range pigs (e.g. Ajayi et al., 1988; Barutzki et al., 1992; Nissen et al., 2011). Permanently confined pigs in traditionally managed indoor herds often have high infection levels with few species, viz. A. suum (primarily in young growing pigs due to acquired resistance in older animals) and Oesophagostomum spp. (predominantly in adult pigs, as infections accumulate with age), whereas $T$. suis and Strongyloides ransomi (threadworm) usually have a low and sporadic occurrence, and Hyostrongylus rubidus (red stomach worm) as well as species with indirect life cycles (e.g. Metastrongylus spp., lungworms) are absent indoor (Nansen and Roepstorff, 1999). Highly industrialised Danish pig herds only have $A$. suum and despite its strong immunogenicity, the highest prevalence is often found in old fatteners or even sows, as no transmission takes place in the farrowing pens, the weaning pens, and sometimes the fattening pens (Roepstorff, 1997). This lack of transmission of $A$. suum to young pigs in modern farrowing units, even though the pens often are contaminated with high numbers of eggs, has been attributed to the lack of favourable micro-environments for egg survival (like 'hot spots' with high relative humidity) (reviewed by Roepstorff, 2003), as a low relative humidity may cause the eggs to collapse before they become infective (Wharton, 1979). It is of particular interest that it has been difficult to demonstrate any significant effect of systematic anthelmintic use on $A$. suum prevalence within Nordic indoor herds (Roepstorff et al., 1999) and that many of the highly industrialised Danish herds have been able to maintain low infection levels without deworming (Roepstorff, 1997).

The production systems are, however, currently undergoing several changes. According to recent Danish legislation aimed at improving animal welfare, loose sows should now be housed in groups (instead of being tethered or otherwise restrained) with access to common resting areas with solid floor and bedding material (instead of fully slatted floors without bedding). The pens of growing pigs and sows should furthermore be equipped with water sprinklers for a daily shower. All these changes and especially the latter must inevitably increase the numbers of hot spots, favourable for egg survival (Thamsborg et al., 2010). Though not yet fully documented, there are indications of a re-emergence of Oesophagostomum sp. within these herds (Haugegaard, 2010) and an outbreak of strongyloidiosis has been observed (Haugegaard, personal communication). If this partly anecdotal evidence holds true, then the only means left for helminth control in the modern production units with a higher level of animal welfare, is regular drug treatment. Unfortunately this is very likely to select for anthelmintic resistance, as already 
observed for Oesophagostomum many years ago (Roepstorff et al., 1987; Bjørn et al., 1990; Gerwert et al., 2002). In this respect, it is thought-provoking that the lack of reports on anthelmintic resistance during the last $10-15$ years may be because Oesophagostomum, which is the most likely candidate for developing resistance, has simply been controlled by intensive housing and not by medication.

\subsection{Helminth challenges in relation to outdoor pig husbandry}

Organic farms have been established as a consumers' reaction against the industrialised husbandry with its high use of chemicals (medication, food additives) and compromised animal welfare. The organic certification legislation vary from country to country, and for Denmark the standards include that pigs; (1) must not be tethered or permanently restrained; (2) should have access to outdoor runs for at least 150 days per year; (3) should have plenty of bedding material when indoor; and (4) diseases must not be prevented by use of veterinary medicine (Anonymous, 2010). As expected, high helminth infection levels are often found in organic pigs (Roepstorff et al., 1992; Christensson, 1996; Carstensen et al., 2002). At present, helminths with indirect life cycles are uncommon in European pigs in organic farming (Roepstorff and Mejer, unpublished) and Oesophagostomum infections do not seem to build up to unacceptable high infection levels, presumably because the free-living larvae survive poorly during warm dry summers (southern Europe) or the cold winters (northern Europe) (Roepstorff and Murrell, 1997; Thomsen et al., 2001). In contrast, A. suum and T. suis are transmitted by eggs that are long-lived and highly resistant to environmental factors. Thus, A. suum eggs have been demonstrated to remain alive and infective in soil for 6 years (Müller, 1953) and 9 years (Mejer and Roepstorff, unpublished), while corresponding figures for T. suis are 5 years (Hill, 1957) and 11 years (Burden et al., 1987). Experimental plot studies in Denmark have demonstrated that the large majority of A. suum and $T$. suis eggs died within the first few months after deposition on pastures and that only a relative small residual population survived for $1-1 \frac{1}{2}$ years, the highest survival being when faeces was deposited in autumn-to-spring (Larsen and Roepstorff, 1999; Kraglund, 1999). Unfortunately, this high initial mortality of the eggs after deposition of faeces does not remove the risk for the grazing and rooting pigs. In fact, repeated depositions may result in a massive accumulation of eggs in the soil, as observed on a Danish farm, when $25 \%$ of a group of pigs turned-out on a heavily contaminated area died due to T. suis (Jensen and Svensmark, 1996). The long-lived A. suum and T. suis eggs is a great challenge for outdoor pig production and even a 2-3 year pasture rotation programme may not be beneficial, as pasture infectivity to tracer pigs has been observed to increase during the first 2-3 years after egg deposition (Mejer, 2006; Fig. 1).

The problem of controlling long-lived eggs is further documented on some Swedish and Danish organic farms, on which almost all pastures were shown to be contaminated with helminth eggs ( $A$. suum, $T$. suis) by simple analyses of $5-10 \mathrm{~g}$ representative soil samples. This was

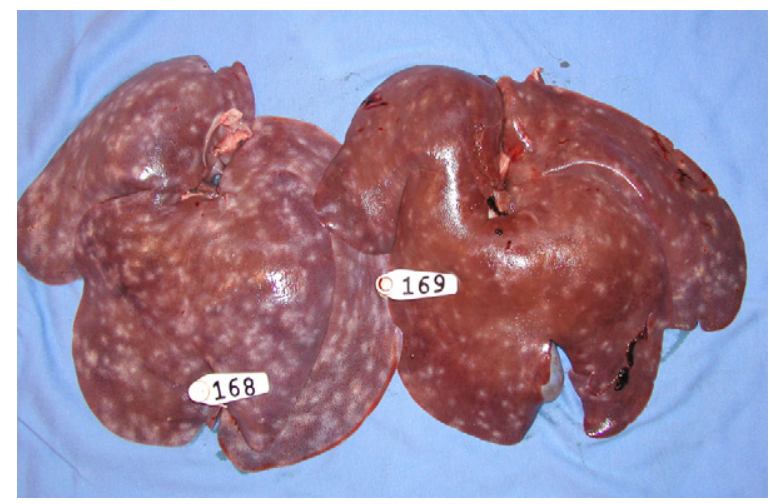

Fig. 1. White spots on livers from two helminth naïve sentinel pigs following 4 days exposure to a paddock, which was contaminated with Ascaris suum eggs 4 years earlier (photo by $\mathrm{H}$. Mejer).

irrespective of whether the pastures had a history of pig grazing or only had been contaminated by spreading pig manure (Andersen, 2009; Lindgren and Roepstorff, unpublished). In Denmark, farmers have so small areas of land that they cannot implement a crop rotation plan of 5-10 years and routine anthelmintic treatments is not an option in an organic context.

As envisaged above, soil analysis for hard-shelled eggs may be very useful for monitoring helminth transmission and understanding the epidemiology, exactly as the corresponding analyses of numbers of trichostrongylid L3-larvae in grass have been for ruminants. Yet, in surveys of human parasites, and even long-term epidemiological investigations, soil samples are usually not included, even though they may be easier to collect than human faecal samples. Apart from few studies demonstrating that eggs may be found indoor, on handles, in kitchen gardens fertilised with human/pig faeces, etc. (e.g. Peng et al., 1996), systematic samplings of surroundings of human dwellings over the different seasons are totally lacking.

\subsection{Worm species and zoonotic aspects}

The relationship and taxonomic status of Ascaris species infecting pigs and humans have been an area of controversy. A range of different methods including morphology, immunology, and biochemistry has been used to address this issue (e.g. Sprent, 1952; Ansel and Thibaut, 1973; Maung, 1973; Kennedy et al., 1987; Hawley and Peanasky, 1992) but all with limited success. More recently the application of different DNA-based methods on sympatric Ascaris populations in Guatemala, China, and Uganda suggests that there is no or limited gene flow between worms infecting humans and pigs (Anderson and Jaenike, 1997; Peng et al., 2005; Nejsum et al., 2010) implying that there are two different populations (species). In contrast, Criscione et al. (2007) identified 4 and 7\% of sympatric worms as being hybrids suggesting that cross-infections take place in areas where humans and pigs live in close proximity. This might not be so surprising since experimental studies has shown that both types of worms are capable of cross-infecting the other host (Takata, 1951; Galvin, 1968). In addition, in areas considered non-endemic 
for the human parasite (e.g. the western part of the world) cases of ascariasis in man have been shown to be due to cross-infections with A. suum (Anderson, 1995; Nejsum et al., 2005; Bendall et al., in press). In Denmark, we have had two case-stories, in which the vegetable gardens of a kindergarten and a small commune were fertilised with pig manure from a nearby farm. In both cases, epidemics of large Ascaris worms were found in the children and subsequent analyses revealed infective eggs in the soil (Roepstorff, unpublished). Even though Ascaris in humans and pigs seems to represent two different species, crossinfections definitely occur and shared cox 1 haplotypes have been described (Peng et al., 2005; Betson et al., 2011). Further studies, where fine scale genetics (many microsatellite markers) are applied on sympatric worm material in order to elucidate cases of cross-infections and occurrence of hybrids, are highly warranted.

In contrast to the Ascaris species, the relationship between Trichuris species in humans and pigs has not been given much attention suggesting that their taxonomic status is settled (i.e. T. trichiura and T. suis in humans and pigs, respectively) and a zoonotic potential of $T$. suis is largely ignored. This is interesting, since adult worms, larvae, and eggs obtained from Trichuris infections of these two hosts are hard or impossible to distinguish based on morphology (Beer, 1973; Soulsby, 1982), as most characters have overlapping ranges and the minor differences (e.g. spicule length) could be host induced (Ooi et al., 1993; Spakulova, 1994; Cutillas et al., 2009). Sequence analysis of the ITS-2 region of sympatric worm material as well as a comparison of the ITS regions of eggs from non-human primates and pig worms, suggests that Trichuris of the two hosts represents two different species but also that $T$. suis may be a zoonosis (Cutillas et al., 2009; Nissen, 2009).

\section{New challenges}

\subsection{Helminth population dynamics in pigs}

Many experimental infection studies with A. suum, T. suis, and Oesophagostomum spp. have been conducted to investigate life cycles, population dynamics, immune responses, etc. All three species have an initial high establishment in helminth naïve pigs, however the course of infections vary considerably. A. suum seems to be most immunogenic, as the large majority of larvae are expelled from the small intestine already at days 14-17 pi (post inoculation), i.e. immediately after having finalised the migration through liver and lungs (Roepstorff et al., 1997; Miquel et al., 2005; Nejsum et al., 2009a), leaving small residual populations of intestinal larvae that grow to maturity. After this expulsion, but not before, the populations are typically strongly aggregated with a relatively high number of worm-free pigs, many pigs harbouring 1-20 worms, and a low number of 'wormy' pigs (Roepstorff et al., 1997; Boes et al., 1998; Nejsum et al., 2009a). When continuously exposed to infective eggs, pigs become increasingly resistant against reinfection, yet some old pigs may still harbour patent worms (e.g. Roepstorff, 1991; Roepstorff et al., 1992). T. suis is also highly immunogenic, but worm expulsion occurs 9-13 weeks pi, i.e. within the patent period (Kringel and Roepstorff, 2006), and aggregation is only found during and after this period of expulsion (Nejsum et al., 2009b). The worm elimination tends to be rather complete in experimental pigs, leaving few very small residual worm burdens within the pigs (Pedersen and Saeed, 2001; Nejsum et al., 2009c). In contrast, Oesophagostomum dentatum has a completely different life strategy, as almost all larvae (at low to moderate levels of exposure) become mature and stay within the host for at least 2-4 months, i.e. as long as the controlled experimental studies have lasted (e.g. Christensen et al., 1995; Roepstorff et al., 1996). This apparently low immunogenicity is reflected in very high prevalences and worm burdens in sows of traditionally managed herds (Raynaud et al., 1975; Roepstorff, 1991; Roepstorff et al., 1992).

These well-described host-parasite relationships have paved the way for studies on predisposition and aggregation (Boes et al., 1998; Coates, 2000), phenomena which are also highly characteristic for corresponding infections in man (Forrester et al., 1990; Anderson et al., 1993; Chan et al., 1992, 1994; Ellis et al., 2007). In studies of human infections with soil transmitted helminths, aggregation and predisposition have been explained by aggregated distributions of eggs in the environment, different risk behaviour of individual persons, and variable levels of acquired resistance (Anderson and Gordon, 1982). Although the combined action of all three factors may contribute to predisposition and aggregation in the field, these phenomena also appear in strictly controlled experimental pig studies. They are thus to be found in experimental A. suum infections as soon as expulsion has acted on the initially established worm burdens, despite all animals receiving the same numbers of infective eggs and all animals being fully helminth naïve at the time of the studies (Roepstorff et al., 1997; Nejsum et al., 2009a).

\subsection{Immune responses and immunomodulation}

The immune responses against $A$. suum have been investigated for decades and have seen a revival with the appearance of modern molecular techniques. Most recently, it has been described that both $A$. suum and $T$. suis elicit strong Th2 skewed responses, which can be measured both systemically (e.g. blood eosinophilia, IL4) and locally (increased IL4, IL6, IL10, and IL13) (Dawson et al., 2005; Kringel et al., 2006; Steenhard et al., 2007). It is reasonable that $A$. suum and $T$. suis have received the most attention, as these species are both highly immunogenic. However, O. dentatum may also prove important to study, for the exact opposite reason, viz. that very large populations of worms may persist in the pig for years apparently without stimulating acquired resistance (e.g. Roepstorff, 1991; Roepstorff et al., 1992). In other words, O. dentatum is able either to avoid stimulation of the host immune system, to manipulate the effector mechanisms of the host immune system, and/or to evade the immunological effector arm(s). Most recently, Andreasen, Petersen and Thamsborg (unpublished) have demonstrated that $O$. dentatum does in fact stimulate mucosal Th2 responses but the response is delayed and with a different cytokine profile than for $T$. suis. In this study, presence of $T$. suis had 
a negative influence on co-infecting $O$. dentatum populations, while, most interesting, $O$. dentatum tended to have a positive influence (more worms and later expulsion) on $T$. suis populations (Andreasen, 2009). Furthermore, specific anti-Oesophagostomum-antibodies were up-regulated in the co-infected group of pigs as compared to pigs infected with $O$. dentatum only. These studies may indicate that $O$. dentatum has developed the ability to modulate the host immune system to increase its survival more efficiently than A. suum and T. suis.

One important effect of specific host immune responses may be acquired resistance, although the underlying mechanisms for worm elimination are still poorly known. According to the Th1/Th2 paradigm, helminths in general stimulate the Th2 arm and down-regulate the Th1 arm, while bacteria and viruses do the opposite. In addition, helminths stimulate regulatory $\mathrm{T}$-cells, which suppress activation of the immune system and maintain immune system homeostasis as well as tolerance to self-antigens. The consequences of the delicate balance between the different arms of the immune system may be of immense practical importance. First, helminth infections may downregulate the Th1 responses against bacteria and viruses thereby reducing the efficacy of vaccinations (Urban et al., 2007), as recently described for Mycoplasma hyopneumoniae vaccination in pigs infected with A. suum (Steenhard et al., 2009). Secondly, the lack of helminth induced immunomodulation in the human populations of the industrialised countries has been hypothesised to contribute to the steep increase in autoimmune diseases, such as inflammatory bowel disease, type 1 diabetes, and multiple sclerosis (reviewed by McKay, 2006; Elliott et al., 2007; Zaccone et al., 2007; Fleming, 2011). This 'Helminth Hypothesis' (Elliott et al., 2007) is derived from the original 'Hygiene Hypothesis' of Strachan (1989), and T. suis is one of the favourites for potential medical use (Reddy and Fried, 2007). T. suis was, among other criteria, originally selected because the infections are self-eliminating in man and the larvae are non-migratory (Elliott et al., 2007). In two clinical trials, Summers et al. (2005a,b) treated (infected) human patients with 2500 infective $T$. suis eggs every 3rd week and found significant remission for both Crohn's Disease and Ulcerative Colitis. Using the same dosing regimen Fleming et al. (in press) obtained promising results on a few patients with multiple sclerosis. Unfortunately, $T$. suis does not seem to have any positive effect on pollen allergy patients (Bager et al., 2010).

\subsection{Genetics of worms and hosts}

The observation of pigs being predisposed to a certain A. suum infection level under controlled experimental conditions suggests that the worm load is under regulation by host genetics (Boes et al., 1998; Coates, 2000). In a pig pedigree study, including 195 pigs from 19 litters (Fig. 2), it was later estimated that the genetic contribution (heritability) accounted for $30-70 \%$ of the variation in A. suum and T. suis worm burdens (Nejsum et al., 2009c). This is in accordance with field studies in a human population in Nepal, where heritabilities of $0.3-0.5$ have been found for both T. trichiura and A. lumbricoides (Williams-Blangero

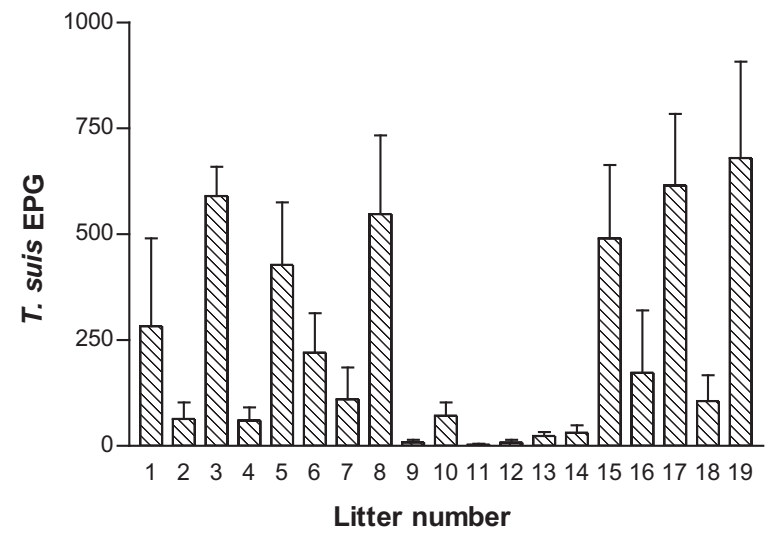

Fig. 2. Trichuris suis faecal egg output (mean $+\mathrm{SE}$ ) week 8 post infection from 19 litters of pigs (totally $n=195$ ). The pigs were trickle inoculated with 5 eggs/ $/ \mathrm{kg} /$ day.

Data from Nejsum et al. (2009b).

et al., 1999, 2002). In this human population, three and two Quantitative Trait Loci (QTL) influencing susceptibility to $A$. lumbricoides and $T$. trichiura infection, respectively, were later identified (Williams-Blangero et al., 2008a,b) confirming the role of host genetics in regulation of helminth infections. Likewise, a genome-scan was performed in the pig population described by Nejsum et al. (2009c) using the Illumina $7 \mathrm{~K}$ porcine SNP-chip. For T. suis faecal egg excretion a candidate QTL was identified on chromosome 13 , whereas the most promising region was on chromosome 4 for the A. suum worm load (Nejsum et al., unpublished). Specific SNPs in these regions are presently been tested in unrelated populations of pigs in order to verify the findings.

For ruminants the genetic contribution to worm load has been acknowledged for many years and are implemented in the breeding programs (Pomroy, 2006). Several studies have identified QTLs with influence on helminth infections in sheep (e.g. Marshall et al., 2009; Dominik et al., 2010) and recently a DNA test has been commercialized (Worm STAR, Pfizer Animal Genetics Ltd.) as a supplementary tool in breeding for helminth resistance in sheep. If similar DNA based tests can be identified in pigs with respect to helminth worm load, this will allow us to produce the 'right animal for the right purpose'. In addition, identifying the genes controlling the worm loads will increase our understanding of the underlying biological pathways in relation to resistance and thereby potentially pave the way for new types of intervention.

In contrast to host genetics, the influence of parasite genetics on the interactions between the parasite and its host has received much less attention. However, as reviewed by Read and Viney (1996) there is no evidence suggesting that helminth genetics should not affect the host's ability to mount a protective response. For example, Koyama and Ito (1996) found that the Th1/Th2 balance in mice depended on the isolate of T. muris and Bellaby et al. (1996) even found that the response was isolatespecific. Likewise, life history traits such as fecundity and survival have shown to vary between different genotypes of Strongyloides ratti (Paterson and Viney, 2003) as have worm expulsion kinetics of the different isolates of T. muris 


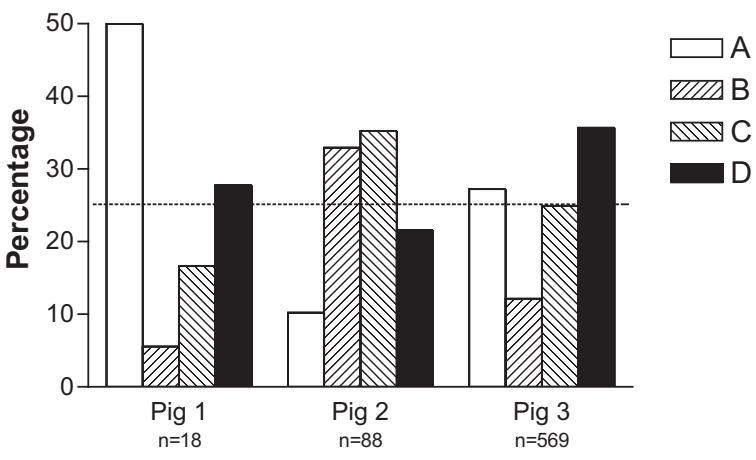

Fig. 3. Numbers of Ascaris suum larvae belonging to 4 mtDNA haplotypes (A-D) at day 28 after inoculation with 500 eggs of each haplotype. Redrawn from Nejsum et al. (2009d).

(Koyama and Ito, 1996) and even production traits vary in sheep infected with different strains of Haemonchus contortus (Hunt et al., 2008). Nejsum et al. (2009d) infected pigs with equal proportions of $A$. suum eggs from 4 females identified by unique mtDNA haplotypes and followed the infections over time, i.e. before, during, and after expulsion of the vast majority of larvae. It was observed that worm abundance and size changed with pig host but also, and even more striking, that the different localities within a single small intestine had different proportions of the 4 worm genotypes (Fig. 3). These studies clearly suggest that the effect of parasite genotypes on the outcome of the host-parasite interactions needs further attention and might explain differences in results obtained from different regions in the world and even within the same country (Hunt et al., 2008).

\subsection{Effects of diet}

Originally, it was a random change in feed type and ensuing problems with establishing experimental infections that set off a series of studies on the impact of dietary carbohydrates on helminth infections in pigs. The initial results indicated that diets with more non-digestible and non-fermentable carbohydrates, such as lignin, favoured $O$. dentatum infections as compared to diets richer in carbohydrates more readily available for microbial fermentation (Petkevičius et al., 1995; Bjørn et al., 1996). One real-life implication of this being that though providing straw or roughage to pigs may improve animal welfare, it may also potentially benefit intestinal worms.

Further studies have since corroborated that fermentable carbohydrates (i.e. prebiotics) may have a substantial negative impact on both establishing and established O. dentatum infections (Petkevičius et al., 1997, 1999, 2001, 2003; Mejer, 2006). Though the mechanism is not fully elucidated, it is believed to be linked to the changes in the physico-chemical properties of the intestinal content and bacterial fermentation end products (i.e. short chain fatty acids), particularly in the caecum and colon as discussed by Petkevičius et al. (1995). Mimicking this process, direct infusion of short chain fatty acids and lactic acid was thus found to eliminate $92 \%$ of established 0 . dentatum (Petkevičius et al., 2004).
Though partly embedded in the intestinal mucosa, both maturing and fully adult $T$. suis have also shown sensitivity to some sources of dietary fermentable carbohydrates (Thomsen et al., 2005, 2007; Petkevičius et al., 2007). Thus, one study showed substantially reduced worm burdens and severely stunted worms (Thomsen et al., 2005; Fig. 4). The latter observation indicates that worm size alone may not always be a valid character for species identification. The overall effect on adult A. suum seems less promising (Petkevičius et al., 1995, 1996; Bjørn et al., 1996; Mejer et al., unpublished) but this may in part reflect that the predilection site is the anterior part of the jejunum where fermentation is minimal (Graham and Åman, 1986) compared to the caecum and colon (reviewed by Flickinger et al., 2003). Larval migration on the other hand does seem to be reduced, potentially because the larvae pass through the caecum and colon (Mejer, 2006; Jensen et al., 2010).

So far fermentable carbohydrate sources such as inulin, a fructan purified from chicory roots, alone or combined with sugar beet fibres have been shown to be effectual (Petkevičius et al., 2003, 2007; Thomsen et al., 2005). In addition, as an alternative to inulin, which is too costly for livestock, both crude, chopped and dried, milled chicory roots have also yielded promising results (Mejer, 2006; Jensen et al., 2010). Though not fully able to eliminate established adult worms, dietary inclusion of crude and dried chicory roots can within just two days almost abolish experimental $O$. dentatum faecal eggs counts (Mejer et al., unpublished). A result that has also been demonstrated twice for Oesophagostomum sp. on-farm, indicating that this principle has a potential for reducing environmental contamination and thereby transmission between pigs (Mejer et al., unpublished).

One challenge of using plant products is that the content of the active components are typically dependent on plant genotype, time of harvest, processing and storage (Ernst et al., 1995; Böhm et al., 2005; Raccuia and Melilli, 2010), all of which may help to explain, why parasitological results can vary between studies. Additionally, even very high levels of fermentable carbohydrates do not completely eliminate helminth infections (Mejer et al., unpublished) and can only fully compete with drugs, if anthelmintic resistance becomes a problem. Overall, there is still an incentive to identify new and more potent feed components, possibly also secondary plant metabolites with antiparasitic effects as described for small ruminants (Brunet et al., 2008).

\subsection{Inactivation of A. suum and T. suis eggs}

As mentioned above, the physico-chemical resistance and the longevity of $A$. suum and $T$. suis eggs create new challenges to control, especially in outdoor production systems. On-farm, one straight forward control initiative is to inactivate all parasite eggs before pastures are fertilised with faecal and bedding material. Such inactivation may be done through thermophilic composting, as both A. suum and $T$. suis eggs only survive for 1 -few hours at $50^{\circ} \mathrm{C}$ and few minutes at $55^{\circ} \mathrm{C}$ (Burden and Ginnivan, 1978; Barnard et al., 1987). Even mesophilic composting may be efficient over time, as at least $A$. suum eggs embry- 

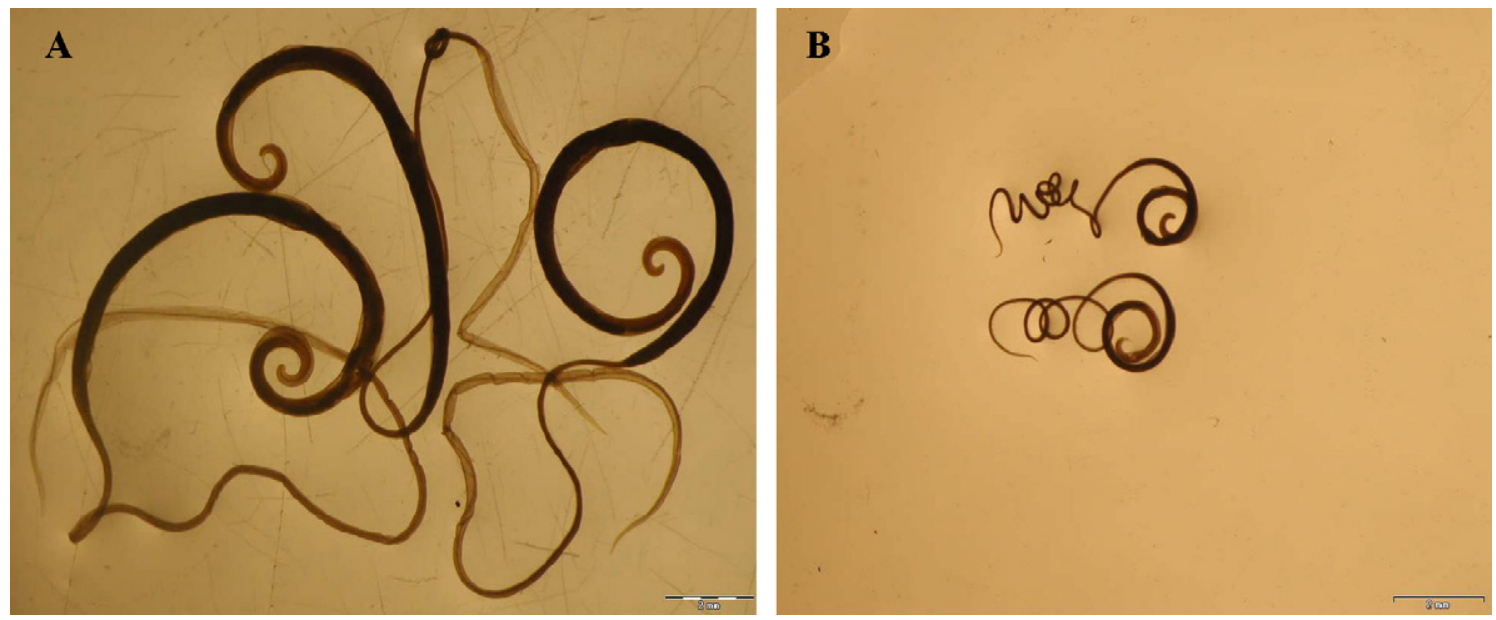

Fig. 4. Trichuris suis recovered from pigs fed a diet rich in poorly degradable carbohydrates (A) and a diet rich in fermentable carbohydrates (B) (photos by L.E. Thomsen).

onated at $28^{\circ} \mathrm{C}$ have much lower performance than eggs developed at lower temperatures (Arene, 1986). Recent observations also indicate that simple anaerobic storage of slurry and solid manure may inactivate A. suum eggs, but long-term storage for about 1 year seems to be necessary at $20^{\circ} \mathrm{C}$ and even longer storage time at $4{ }^{\circ} \mathrm{C}$ (Katakam and Roepstorff, unpublished). Another approach, which should be investigated further, is the use of egg-predacious microfungi. Several microfungi are used commercially to combat plant-parasitic nematodes in large-scale monocultures, and for example Pochonia chlamydosporia and Paecilomyces lilacinus have also been shown to attack $A$. suum, Trichuris vulpis, and Toxocara canis eggs in vitro (Araújo et al., 2008; Carvalho et al., 2010; Silva et al., 2010). Hopefully, microfungi can efficiently inactivate large numbers of thick-shelled eggs in stored manure or even on contaminated pastures and thereby help control the parasites in a sustainable way. The easy availability of commercial products, for horticultural use, may prove useful in this context.

\section{Future helminth control}

From the selected topics discussed above, it is clear that there is a series of challenges as well as opportunities within research on the three major helminths of pigs. The recent changes in indoor and outdoor pig production systems call for veterinary parasitologists to develop new strategies for helminth control. Such strategies have until now, mostly relied on routine use of anthelmintics administered to selected age groups, e.g. pigs at weaning and half way in the fattening period and breeding stock before farrowing and/or every 3-6 months. But due to the lack of evidence for parasitological and economic benefits, routine deworming has been replaced by helminth surveillance in many Danish pig industries, as suggested by Roepstorff (1997), or treatment has simply stopped. For the new animal-friendly housing and not least for alternative outdoor systems, both of which are highly favourable to helminth transmission, control is needed and it will be very risky to rely on anthelmintics alone, as anthelmintic resistance will inevitably develop - and for organic farms routine preventive treatment is not an option. Therefore, there is a strong need for elaborating and testing alternative control measures, such as using more resistant genotypes for breeding (Nejsum et al., 2009c), feeding the pigs with fermentable carbohydrates to reduce worm burdens (Petkevičius et al., 2001, 2003, 2007; Thomsen et al., 2005; Mejer, 2006), and inactivate hard-shelled nematode eggs within the surrounding environment, e.g. by egg predacious microfungi (Gortari and Hours, 2008). For outdoor pigs, handling and processing manure in a way that inactivates the hard-shelled eggs, should be revisited to provide farmers knowledge of means to avoid contaminating the pastures. All these alternative and sustainable control measures need to be further tested and the most promising should be combined with intelligent use of anthelmintics in an integrated helminth control program.

\section{Conflict of interest statement}

The authors declare no conflicts of interest.

\section{References}

Ajayi, J.A., Arabs, W.L., Adeleye, G.A., 1988. Helminths and protozoa of pigs on the Jos Plateau, Nigeria: occurrence, age incidence and seasonal distribution. Bull. Anim. Health Prod. Afr. 36, 47-54.

Andersen, S.N., 2009. Occurrence of free-living helminth eggs and larvae in organic pig farms. Master Diss. University of Copenhagen.

Anderson, R.M., Gordon, D.M., 1982. Processes influencing the distribution of parasite numbers within host populations with special emphasis on parasite-induced host mortalities. Parasitology 85, 373-398.

Anderson, T.J.C., 1995. Ascaris infections in humans from North America: molecular evidence for cross-infection. Parasitology 110, 215-219.

Anderson, T.J.C., Jaenike, J., 1997. Host specificity, evolutionary relationships and macrogeographic differentiation among Ascaris populations from humans and pigs. Parasitology 115, 325-342.

Anderson, T.J.C., Romero-abal, M.E., Jaenike, J., 1993. Genetic structure and epidemiology of Ascaris populations: patterns of host affiliation in Guatemala. Parasitology 107, 319-334.

Andreasen, A., 2009. Concurrent experimental infection with Oesophagostomum dentatum and Trichuris suis in pigs: effects on parasite population dynamics. Master Diss. Faculty Life Sciences. University of Copenhagen, p. 71. 
Anonymous, 2010. Vejledning om økologisk jordbrugsproduktion. Guidelines for organic husbandry and agriculture. Danish Plant Inspectorate, Ministery of Food, Agriculture and Fisheries, 2800 Kgs. Lyngby, Denmark. ISBN 978-87-7083-983-9, p. 175.

Ansel, M., Thibaut, M., 1973. Value of the specific distinction between Ascaris lumbricoides Linne 1758 and Ascaris suum Goeze 1782. Int. J. Parasitol. 3, 317-319.

Araújo, J.V., Braga, F.R., Araújo, J.M., Silva, A.R., Tavela, A.O., 2008. In vitro evaluation of the effect of the nematophagous fungi Duddingtonia flagrans, Monacrosporium sinense and Pochonia chlamydosporia on Ascaris suum eggs. Parasitol. Res. 102, 787-790.

Arene, F.O.I., 1986. Ascaris suum: influence of embryonation temperature on the viability of the infective larva. J. Therm. Biol. 11, 9-15.

Bager, P., Arnved, J., Rønborg, S., Wohlfahrt, J., Poulsen, L.K., Westergaard, T., Petersen, H.W., Kristensen, B., Thamsborg, S.M., Roepstorff, A., Kapel, C., Melbye, M., 2010. Trichuris suis ova therapy for allergic rhinitis: a randomized, double-blind, placebo-controlled clinical trial. J. Allergy Clin. Immunol. 125, 123-130.

Barnard, R.J., Bier, J.W., Jackson, G.J., McClure, F.D., 1987. Ascaris lumbricoides suum: thermal death time of unembryonated eggs. Exp. Parasitol. 64, 120-122.

Barutzki, D., Randelzhofer, A., Gothe, R., 1992. Artenspektrum und Befallshäufigkeit von Helminthen bei Mutterschweinen und ihren Ferkeln in Süddeutschland. Tierärztl. Umsch. 47, 179-190.

Beer, R.J.S., 1973. Morphological description of the egg and larval stages of Trichuris suis Schrank, 1788. Parasitology 67, 263-278.

Bellaby, T., Robinson, K., Wakelin, D., 1996. Induction of differential Thelper-cell responses in mice infected with variants of the parasitic nematode Trichuris muris. Infect. Immun. 64, 791-795.

Bendall, R.P., Barlow, M., Betson, M., Stothard, J.R. Nejsum, P. Zoonotic Ascaris infection in the United Kingdom: an epidemiological and molecular investigation. Emerging Infect. Dis., in press.

Betson, M., Halstead, F.D., Nejsum, P., Imison, E., Khamis, I.S., SousaFigueiredo, J.C., Rollinson, D., Stothard, J.R., 2011. A molecular epidemiological investigation of Ascaris on Unguja, Zanzibar using isoenyzme analysis, DNA barcoding and microsatellite DNA profiling. Trans. R. Soc. Trop. Med. Hyg., doi:10.1016/j.trstmh.2011.04.009, in press.

Bjørn, H., Roepstorff, A., Waller, P.J., Nansen, P., 1990. Resistance to levamisole and cross resistance between pyrantel and levamisole in Oesophagostomum quadrispinulatum and Oesophagostomum dentatum of pigs. Vet. Parasitol. 37, 21-30.

Bjørn, H., Roepstorff, A., Nansen, P., 1996. A possible influence of diet composition on the establishment of nematodes in pigs. Vet. Parasitol. 63, 167-171.

Boes, J., Helwigh, A.B., 2000. Animal models of intestinal nematode infections of humans. Parasitology 121, S97-S111.

Boes, J., Medley, G.F., Eriksen, L., Roepstorff, A., Nansen, P., 1998. Distribution of Ascaris suum in experimentally and naturally infected pigs and comparison with Ascaris lumbricoides infections in humans. Parasitology $117,589-596$.

Brunet, S., Jackson, F., Hoste, H., 2008. Effects of sainfoin (Onobrychis viciifolia) extract and monomers of condensed tannins on the association of abomasal nematode larvae with fundic explants. Int. J. Parasitol. 38, 783-790.

Burden, D.J., Ginnivan, M.J., 1978. The destruction of pig helminth ova and larvae in a slurry treatment process. Vet. Rec. 103, 373-375.

Burden, D.J., Hammet, N.C., Brookes, P.A., 1987. Field observations on the longevity of Trichuris suis ova. Vet. Rec. 121, 43

Böhm, A., Kaiser, I., Trebstein, A., Henle, T., 2005. Heat-induced degradation of inulin. Eur. Food Res. Technol. 220, 466-471.

Carstensen, L., Vaarst, M., Roepstorff, A., 2002. Endoparasite infections in Danish organic swine herds. Vet. Parasitol. 106, 253-264.

Carvalho, R.O., Araújo, J.V., Braga, F.R., Araujo, J.M., Alves, C.D.F., 2010. Ovicidal activity of Pochonia chlamydosporia and Paecilomyces lilacinus on Toxocara canis eggs. Vet. Parasitol. 169, 123-127.

Chan, L., Kan, S.P., Bundy, D.A.P., 1992. The effect of repeated chemotherapy on age-related predisposition to Ascaris lumbricoides and Trichuris trichiura. Parasitology 104, 371-377.

Chan, L., Bundy, D.A.P., Kan, S.P., 1994. Genetic relatedness as a determinant of predisposition to Ascaris lumbricoides and Trichuris trichiura infection. Parasitology 108, 77-80.

Christensen, C.M., Barnes, E.H., Nansen, P., Roepstorff, A., Slotved, H.C., 1995. Experimental Oesophagostomum dentatum infection in the pig: worm populations resulting from single infections with three doses of larvae. Int. J. Parasitol. 25, 1491-1498.

Christensson, D.A., 1996. Djurmiljö och parasitförekomst i utegrishållning - inventering på 12 gårdar: parasitförekomst. Jordbruksinformation $5,26-27$.
Coates, S., 2000. Modelling the population dynamics of Ascaris suum in pigs. Ph.D. Diss. The Royal Vet. Agri. University, Denmark, and The University of Warwick, UK, p. 162.

Criscione, C.D., Anderson, J.D., Sudimack, D., Peng, W., Jha, B., WilliamsBlangero, S., Anderson, T.J.C., 2007. Disentangling hybridization and host colonization in parasitic roundworms of humans and pigs. Proc. R. Soc. Biol. Sci. Ser. B 274, 2669-2677.

Cutillas, C., de Callejon, R., Tewes, R.M., Ubeda, J.M., Ariza, C., Guevara, D.C., 2009. Trichuris suis and Trichuris trichiura are different nematode species. Acta Trop. 111, 299-307.

Dawson, H.D., Beshah, E., Nishi, S., Solano-Aguilar, G.I., Morimoto, M., Zhao, A., Madden, K.B., Ledbetter, T.K., Dubey, J.P., Shea-Donohue, T., Lunney, J.K., Urban, J.F., 2005. Localized multigene expression patterns support an evolving Th1/Th2-like paradigm in response to infections with Toxoplasma gondii and Ascaris suum. Infect. Immun. 73, 1116-1128.

de Silva, N.R., Brooker, S., Hotez, P.J., Montresor, A., Engels, D., Savioli, L., 2003. Soil-transmitted helminth infections: updating the global picture. Trends Parasitol. 19, 547-551.

Dominik, S., Hunt, P.W., McNally, J., Murrell, A., Hall, A., Purvis, I.W., 2010. Detection of quantitative trait loci for internal parasite resistance in sheep. I. Linkage analysis in a Romney X Merino sheep backcross population. Parasitology 137, 1275-1282.

Elliott, D.E., Summers, R.W., Weinstock, J.V., 2007. Helminths as governors of immune-mediated inflammation. Int. J. Parasitol. 37, 457-464.

Ellis, M.K., Raso, G., Li, Y.S., Rong, Z., Chen, H.G., McManus, D.P., 2007. Familial aggregation of human susceptibility to co- and multiple helminth infections in a population from the Poyang Lake region, China. Int. J. Parasitol. 37, 1153-1161.

Ernst, M., Chatterton, N.J., Harrison, P.A., 1995. Carbohydrate changes in chicory (Chicorium intybus L. var. foliosum) during growth and storage. Sci. Horticult. 63, 251-261.

Fleming, J.O., 2011. Helminths and multiple sclerosis: will old friends give us new treatments for MS? J. Neuroimmunol. 233, 3-5.

Fleming, J.O., Isaak, A., Lee, J.E., Luzzio, C.C., Carrithers, M.D., Cook, T.D., Field, A.S., Boland, J., Fabry, Z. Probiotic helminth administration in relapsing-remitting multiple sclerosis: a phase I study. Mult. Scler., doi:10.1177/1352458511398054, in press.

Flickinger, E.A., Van Loo, J., Fahey, G.C., 2003. Nutritional responses to the presence of inulin and oligofructose in the diets of domesticated animals: a review. Crit. Rev. Food Sci. Nutr. 43, 19-60.

Forrester, J.E., Scott, M.E., Bundy, D.A.P., Golden, M.H.N., 1990. Predisposition of individuals and families in Mexico to heavy infection with Ascaris lumbricoides and Trichuris trichiura. Trans. R. Soc. Trop. Med. Hyg. 84, 272-276.

Galvin, T.J., 1968. Development of human and pig Ascaris in the pig and rabbit. J. Parasitol. 54, 1085-1091.

Gerwert, S., Failing, K., Bauer, C., 2002. Prevalence of levamisole and benzimidazole resistance in Oesophagostomum populations of pigbreeding farms in North Rhine-Westphalia, Germany. Parasitol. Res. $88,63-68$

Gortari, M.C., Hours, R.A., 2008. Fungal chitinases and their biological role in the antagonism onto nematode eggs: a review. Mycol. Prog. 7, 221-238.

Graham, H., Åman, P., 1986. Composition and digestion in the pig gastrointestinal trarct of Jerusalem artichoke tubers. Food Chem. 22, 67-76.

Hale, O.M., Stewart, T.B., 1979. Influence of an experimental infection of Trichuris suis on performance of pigs. J. Anim. Sci. 49, 1000-1010.

Hale, O.M., Stewart, T.B., Marti, O.G., Wheat, B.E., McCormick, W.C., 1981. Influence of an experimental infection of nodular worms (Oesophagostomum spp.) on performance in pigs. J. Anim. Sci. 52, 316-322.

Hale, O.M., Stewart, T.B., Marti, O.G., 1985. Influence of an experimental infection of Ascaris suum on performance of pigs. J. Anim. Sci. 60 , $220-225$.

Haugegaard, J., 2010. Prevalence of nematodes in Danish industrialized sow farms with loose housed sows in dynamic groups. Vet. Parasitol. $168,156-159$

Hawley, J.H., Peanasky, R.J., 1992. Ascaris suum: are trypsin inhibitors involved in species specificity of ascarid nematodes? Exp. Parasitol. 75, 112-118.

Hill, H.C., 1957. The survival of swine whipworm eggs in hog lots. J. Parasitol. 43, 104.

Hunt, P.W., Knox, M.R., Le Jambre, L.F., McNally, J., Anderson, L.J., 2008. Genetic and phenotypic differences between isolates of Haemonchus contortus in Australia. Int. J. Parasitol. 38, 885-900.

Jensen, A.N., Mejer, H., Mølbak, L., Langkjær, M., Jensen, T.K., Angen, Ø., Martinussen, T., Klitgaard, K., Baggesen, D.L., Thamsborg, S.M., Roepstorff, A., 2010. The effect of a diet with fructan-rich chicory roots on intestinal helminths and microbiota with special focus on Bifi- 
dobacteria and Campylobacter in piglets around weaning. Animal. http://journals.cambridge.org/repo_A79IcSjZ.

Jensen, T.K., Svensmark, B., 1996. Trichuriasis hos udendørs slagtesvin. Vet. Inform. 2, 3-7.

Kennedy, M.W., Qureshi, F., Haswell-Elkins, M., Elkins, D.B., 1987. Homology and heterology between the secreted antigens of the parasitic larval stages of Ascaris lumbricoides and Ascaris suum. Clin. Exp. Immunol. 67, 20-30.

Koyama, K., Ito, Y., 1996. Comparative studies on immune responses to infection in susceptible B10.BR mice infected with different strains of the murine nematode parasite Trichuris muris. Parasite Immunol. 18, 257-263.

Kraglund, H.-O., 1999. Survival, development and dispersal of the freeliving stages of Ascaris suum, Oesophagostomum dentatum and Trichuris suis at the pasture, Ph.D. Diss. The Royal Vet. Agric. University, Copenhagen, Denmark, p. 88.

Kringel, H., Roepstorff, A., 2006. Trichuris suis population dynamics following a primary experimental infection. Vet. Parasitol. 139, 132-139.

Kringel, H., Iburg, T., Dawson, H., Aasted, B., Roepstorff, A., 2006. A time course study of immunological responses in Trichuris suis infected pigs demonstrates induction of a local type 2 response associated with worm burden. Int. J. Parasitol. 36, 915-924.

Larsen, M.N., Roepstorff, A., 1999. Seasonal variation in development and survival of Ascaris suum and Trichuris suis eggs on pastures. Parasitology $119,209-220$.

Marshall, K., Maddox, J.F., Lee, S.H., Zhang, Y., Kahn, L., Graser, H.U., Gondro, C., Walkden-Brown, S.W., Van Der Werf, J.H.J., 2009. Genetic mapping of quantitative trait loci for resistance to Haemonchus contortus in sheep. Anim. Genet. 40, 262-272.

Maung, M., 1973. Ascaris lumbricoides Linné, 1758 and Ascaris suum Goeze 1782: morphological differences between specimens obtained from man and pig. Southeast Asian J. Trop. Med. Public Health 4, 41-45.

McKay, D.M., 2006. The beneficial helminth parasite? Parasitology 132 , $1-12$.

Mejer, H., 2006. Transmission, infection dynamics and alternative control of helminths in organic swine. Ph.D. Diss. The Royal Vet. Agric. University, p. 148.

Miquel, N., Roepstorff, A., Bailey, M., Eriksen, L., 2005. Host immune reactions and worm kinetics during the expulsion of Ascaris suum in pigs. Parasite Immunol. 27, 79-88.

Müller, G., 1953. Untersuchungen über die Lebensdauer von Askarideneiern in Gartenerde. Zentralbl. Bakteriol. [orig.] 159, 377-379.

Nansen, P., Roepstorff, A., 1999. Parasitic helminths of the pig: factors influencing transmission and infection levels. Int. J. Parasitol. 29, 877-891.

Nejsum, P., Parker, E.D., Frydenberg, J., Roepstorff, A., Boes, J., Haque, R., Astrup, I., Prag, J., Skov Sørensen, U.B., 2005. Ascariasis is a zoonosis in Denmark. J. Clin. Microbiol. 43, 1142-1148.

Nejsum, P., Thamsborg, S.M., Petersen, H.H., Kringel, H., Fredholm, M., Roepstorff, A., 2009a. Population dynamics of Ascaris suum in trickleinfected pigs. J. Parasitol. 95, 1048-1053.

Nejsum, P., Thamsborg, S.M., Petersen, H.H., Kringel, H., Fredholm, M., Roepstorff, A., 2009b. Population dynamics of Trichuris suis in trickleinfected pigs. Parasitology 136, 691-697.

Nejsum, P., Roepstorff, A., Jørgensen, C.B., Fredholm, M., Göring, H.H.H., Anderson, T.J.C., Thamsborg, S.M., 2009c. High heritability for Ascaris and Trichuris infection levels in pigs. Heredity 102, 357-364.

Nejsum, P., Roepstorff, A., Anderson, T.J.C., Jørgensen, C.B., Fredholm, M. Thamsborg, S.M., 2009d. The dynamics of genetically marked Ascaris suum infections in pigs. Parasitology 136, 193-201.

Nejsum, P., Bertelsen, M.F., Betson, M., Stothard, J.R., Murrell, K.D., 2010. Molecular evidence for sustained transmission of zoonotic Ascaris suum among zoo chimpanzees (Pan troglodytes). Vet. Parasitol. 171, 273-276.

Nissen, S., 2009. Morphological and genetic diversity of whipworms (Trichuris spp.) recovered from pigs and humans. Master Diss. Faculty of Life Sciences, University of Copenhagen, p. 42.

Nissen, S., Poulsen, I.H., Nejsum, P., Olsen, A., Roepstorff, A., Rubaire-Akiiki, C., Thamsborg, S.M., 2011. Prevalence of gastrointestinal nematodes in growing pigs in Kabale District in Uganda. Trop. Anim. Health Prod. $43,567-572$.

Ooi, H.K., Tenora, F., Itoh, K., Kamiya, M., 1993. Comparative study of Trichuris trichiura from non-human primates and from man, and their difference with T. suis. J. Vet. Med. Sci. 55, 363-366.

Paterson, S., Viney, M.E., 2003. Functional consequences of genetic diversity in Strongyloides ratti infections. Proc. R. Soc. Biol. Ser. B 270, $1023-1032$

Pedersen, S., Saeed, I., 2001. Acquired immunity to Trichuris suis infection in pigs. Parasitology 123, 95-101.
Peng, W., Zhou, X., Cui, X., Crompton, D.W.T., Whitehead, R.R., Xiong, J. Wu, H., Peng, J., Yang, Y., Wu, W., Xu, K., Yan, Y., 1996. Ascaris, people and pigs in a rural community of Jiangxi Province, China. Parasitology 113, 545-557.

Peng, W.D., Yuan, K., Hu, M., Zhou, X.M., Gasser, R.B., 2005. Mutation scanning-coupled analysis of haplotypic variability in mitochondrial DNA regions reveals low gene flow between human and porcine Ascaris in endemic regions of China. Electrophoresis 26, 4317-4326.

Petkevičius, S., Bjørn, H., Roepstorff, A., Nansen, P., Bach Knudsen, K.E., Barnes, E.H., Jensen, K., 1995. The effect of two types of diet on populations of Ascaris suum and Oesophagostomum dentatum in experimentally infected pigs. Parasitology 111, 395-402.

Petkevičius, S., Bach Knudsen, K.E., Nansen, P., Roepstorff, A., 1996. The influence of diet on infections with Ascaris suum and Oesophagostomum dentatum in pigs on pasture. Helminthologia 33, 173-180.

Petkevičius, S., Bach Knudsen, K.E., Nansen, P., Roepstorff, A., Skjøth, F., Jensen, K., 1997. The impact of diets varying in carbohydrates resistant to endogenous enzymes and lignin on populations of Ascaris suum and Oesophagostomum dentatum in pigs. Parasitology 114, 555-568.

Petkevičius, S., Nansen, P., Bach Knudsen, K.E., Skjøth, F., 1999. The effect of increasing levels of insoluble dietary fibre on the establishment and persistence of Oesophagostomum dentatum in pigs. Parasite 6, 17-26.

Petkevičius, S., Bach Knudsen, K.E., Nansen, P., Murrell, K.D., 2001. The effect of dietary carbohydrates with different digestibility on the populations of Oesophagostomum dentatum in the intestinal tract of pigs. Parasitology 123, 315-324.

Petkevičius, S., Bach Knudsen, K.E., Murrell, K.D., Wachmann, H., 2003. The effect of inulin and sugar beet fibre on Oesophagostomum dentatum infection in pigs. Parasitology 127, 61-68.

Petkevičius, S., Murrell, K.D., Bach Knudsen, K.E., Jørgensen, H., Roepstorff, A., Laue, A., Wachmann, H., 2004. Effects of short-chain fatty acids and lactic acids on survival of Oesophagostomum dentatum in pigs. Vet. Parasitol. 122, 293-301.

Petkevičius, S., Thomsen, L.E., Bach Knudsen, K.E., Murrell, K.D., Roepstorf, A., Boes, J., 2007. The effect of inulin on new and on patent infections of Trichuris suis in growing pigs. Parasitology 134, 121-127.

Pomroy, W.E., 2006. Anthelmintic resistance in New Zealand: a perspective on recent findings and options for the future. N. Z. Vet. J. 54, 265-270.

Raccuia, S.A., Melilli, M.G., 2010. Seasonal dynamics of biomass, inulin, and water-soluble sugars in the root of Cynara cardunculus L. Field Crops Res. 116, 47-153.

Raynaud, J.P., Sennelier, J., Irisarri, E., 1975. Post-natal parasitic infection of piglets in contact with infected mothers. A study of 20 sows and 164 piglets, 42 of which were killed at weaning. Folia Vet. Lat. 5, 412-429.

Read, A.F., Viney, M.E., 1996. Helminth immunogenetics: why bother? Parasitol. Today $12,337-343$.

Reddy, A., Fried, B., 2007. The use of Trichuris suis and other helminth therapies to treat Crohn's disease. Parasitol. Res. 100, 921-927.

Roepstorff, A., 1991. Transmission of intestinal helminths in Danish sow herds. Vet. Parasitol. 39, 149-160.

Roepstorff, A., 1997. Helminth surveillance as a prerequisite for anthelmintic treatment in intensive sow herds. Vet. Parasitol. 73, 139-151.

Roepstorff, A., 2003. Ascaris suum in Pigs: Population Biology and Epidemiology. Dr. Diss. The Royal Vet. Agri. University, p. 112.

Roepstorff, A., Murrell, K.D., 1997. Transmission dynamics of helminth parasites of pigs on continuous pasture: Oesophagostomum dentatum and Hyostrongylus rubidus. Int. J. Parasitol. 27, 553-562.

Roepstorff, A., Bjørn, H., Nansen, P., 1987. Resistance of Oesophagostomum spp. in pigs to pyrantel citrate. Vet. Parasitol. 24, 229-239.

Roepstorff, A., Jørgensen, R.J., Nansen, P., Henriksen, S.A., Skovgaard Petersen, J., Andreasen, M., 1992. Parasitter hos økologiske svin. Project Report. Landsudvalget for Svin, Danske Slagterier, p. 36.

Roepstorff, A., Bjørn, H., Nansen, P., Barnes, E.H., Christensen, C.M., 1996 Experimental Oesophagostomum dentatum infections in the pig: worm populations resulting from trickle infections with three dose levels of larvae. Int. J. Parasitol. 26, 399-408.

Roepstorff, A., Eriksen, L., Slotved, H.-C., Nansen, P., 1997. Experimental Ascaris suum infection in the pig: worm population kinetics following single inoculations with three doses of infective eggs. Parasitology $115,443-452$.

Roepstorff, A., Nilsson, O., O'Callaghan, C.J., Oksanen, A., Gjerde, B., Richter, S.H., Örtenberg, E., Christensson, D., Nansen, P., Eriksen, L., Medley, G.F., 1999. Intestinal parasites in swine in the Nordic countries: multilevel modelling of Ascaris suum infections in relation to production factors. Parasitology 119, 521-534.

Silva, A.R., Araújo, J.V., Braga, F.R., Alves, C.D.F., Frassy, L.N., 2010. In vitro ovicidal activity of the nematophagous fungi Duddingtonia fla- 
grans, Monacrosporium thaumasium and Pochonia chlamydosporia on Trichuris vulpis eggs. Vet. Parasitol. 172, 76-79.

Soulsby, E.J.L., 1982. Helminths. Arthropods and Protozoa of Domesticated Animals, 7th ed. Balliere Tindall, London, UK, p. 809.

Spakulova, M., 1994. Discriminant analysis as a method for the numerical evaluation of taxonomic characters in male trichurid nematodes. Syst. Parasitol. 29, 113-119.

Sprent, J.F.A., 1952. Anatomical distinction between human and pig strains of Ascaris. Nature 170, 627-628.

Steenhard, N.R., Kringel, H., Roepstorff, A., Thamsborg, S.M., Jungersen, G., 2007. Parasite-specific IL-4 responses in Ascaris suum and Trichuris suis-infected pigs evaluated by ELISPOT. Parasite Immunol. 29, 535-538.

Steenhard, N.R., Jungersen, G., Kokotovic, B., Beshah, E., Dawson, H.D., Urban, J.F., Roepstorff, A., Thamsborg, S.M., 2009. Ascaris suum infection negatively affects the response to a Mycoplasma hyopneumoniae vaccination and subsequent challenge infection in pig. Vaccine 27 , 5161-5169.

Strachan, D.P., 1989. Hay fever, hygiene and household size. Br. Med. J. 299, 1259-1260.

Summers, R.W., Elliott, D.E., Urban, J.F., Thompson, R.A., Weinstock, J.V., 2005a. Trichuris suis therapy in Crohn's disease. Gut 54, 87-90.

Summers, R.W., Elliott, D.E., Urban, J.F., Thompson, R.A., Weinstock, J.V., 2005b. Trichuris suis therapy for active Ulcerative Colitis: a randomized controlled trial. Gastroenterology 128, 825-832.

Takata, I., 1951. Experimental infection of man with Ascaris of man and the pig. Kitasato Arch. Exp. Med. 23, 49-59.

Thamsborg, S.M., Roepstorff, A., 2003. Parasite problems in organic livestock production systems and options for control. J. Parasitol. (suppl.) 89, S277-S284.

Thamsborg, S.M., Roepstorff, A., Nejsum, P., Mejer, H., 2010. Alternative approaches to control of parasites in livestock: Nordic and Baltic perspectives. Acta Vet. Scand. 52 (Suppl. 1), 1-5.

Thomsen, L.E., Mejer, H., Wendt, S., Roepstorff, A., Hindsbo, O., 2001. The influence of stocking rate on transmission of helminth parasites in pigs on permanent pasture during two consecutive summers. Vet. Parasitol. 99, 129-146.

Thomsen, L.E., Petkevičius, S., Bach Knudsen, K.E., Roepstorff, A., 2005. The influence of dietary carbohydrates on experimental infection with Trichuris suis in pigs. Parasitology 131, 857-865.

Thomsen, L.E., Bach Knudsen, K.E., Jensen, T.K., Christensen, A.S., Møller, K., Roepstorff, A., 2007. The effect of fermentable carbohydrates on experimental swine dysentery and whip worm infections in pig. Vet. Microbiol. 19, 152-163.

Urban, J.F., Steenhard, N.R., Solano-Aguilar, G.I., Dawson, H.D., Iweala, O.I., Nagler, C.R., Noland, G.S., Kumar, N., Anthony, R.M., Shea-Donohue, T., Weinstock, J., Gause, W.C., 2007. Infection with parasitic nematodes confounds vaccination efficacy. Vet. Parasitol. 148, 14-20.

Wharton, D.A., 1979. Ascaris sp.: water loss during dessication of embryonating eggs. Exp. Parasitol. 48, 398-406.

Williams-Blangero, S., Subedi, J., Upadhayay, R.P., Manral, D.B., Rai, D.R., Jha, B., Robinson, E.S., Blangero, J., 1999. Genetic analysis of susceptibility to infection with Ascaris lumbricoides. Am. J. Trop. Med. Hyg. 60, 921-926.

Williams-Blangero, S., McGarvey, S.T., Subedi, J., Wiest, P.M., Upadhayay, R.P., Rai, D.R., Jha, B., Olds, G.R., Guanling, W., Blangero, J., 2002. Genetic component to susceptibility to Trichuris trichiura: evidence from two Asian populations. Genet. Epidemiol. 22, 254-264.

Williams-Blangero, S., VandeBerg, J.L., Subedi, J., Jha, B., Correa-Oliveira, R., Blangero, J., 2008a. Localization of multiple quantitative trait loci influencing susceptibility to infection with Ascaris lumbricoides. J. Infect. Dis. 197, 66-71.

Williams-Blangero, S., VandeBerg, J.L., Subedi, J., Jha, B., Dyer, T.D., Blangero, J., 2008b. Two quantitative trait loci influence whipworm (Trichuris trichiura) infection in a Nepalese population. J. Infect. Dis. 197, 1198-1203.

Zaccone, P., Burton, O.T., Cooke, A., 2007. Interplay of parasitedriven immune responses and autoimmunity. Trends Parasitol. 24, 35-42. 